\title{
Green Synthesized Silver Nanoparticles Using Anise (Pimpinella anisum L.) have Antibacterial Effects
}

\author{
Rashnaei Nassir $^{1}$ (D), Siadat Seyed Davar ${ }^{2}$ (D), Akhavan Sepahi Abbas ${ }^{3}$ (D), Mirzaee Mohsen ${ }^{4}$, Bahramali Golnaz $^{1 * *}$ (D) \\ , Arab Joshaghani Abolfazl ${ }^{5 *}$ (D)
}

${ }^{1}$ Department of Hepatitis and AIDS, Pasteur Institute of Iran, Tehran, Iran. ${ }^{2}$ Department of Mycobacteriology and Pulmonary Research, Pasteur Institute of Iran, Tehran, Iran. ${ }^{3}$ Department of Microbiology, Faculty of Biological Sciences, Islamic Azad University TNB, Tehran, Iran. ${ }^{4}$ Department of Laboratory Science, Borujerd Branch, Islamic Azad University, Borujerd, Iran. ${ }^{5}$ Department of Biology, Borujerd Branch, Islamic Azad University, Borujerd, Iran.

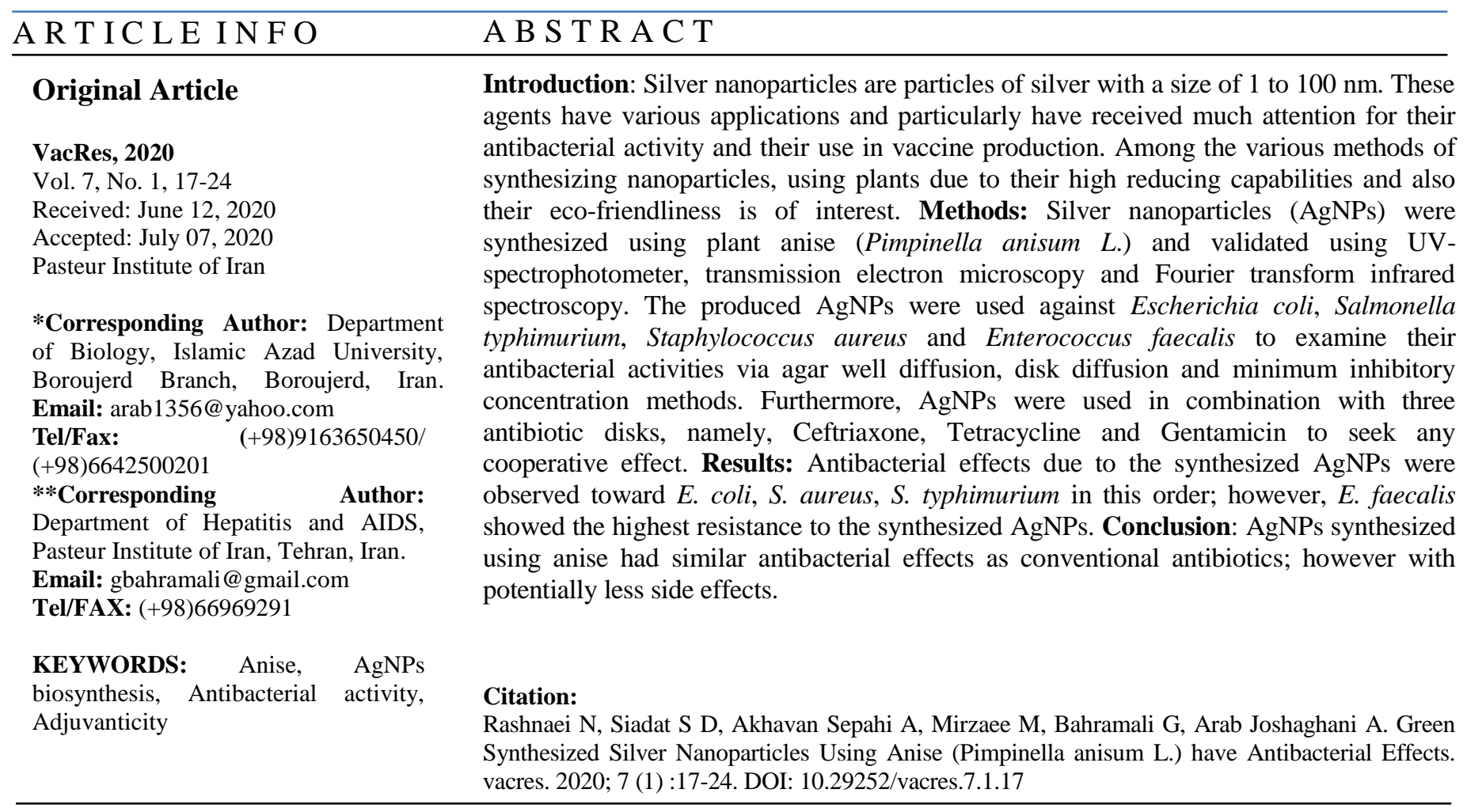

\section{INTRODUCTION}

Nanotechnology has gained importance in many fields of science and technology in recent years [1]. Nanoparticles are particles with a size of 1 to 100 nanometers [2]. Some metal nanoparticles such as silver, gold and platinum are broadly applied in medicine and pharmaceutical industries as well as common consumables such as detergents and cosmetics [3, 4]. Nanoparticles are also used in the production of new generation of vaccines as both antigen nanocarriers and adjuvants[5-7]. Nowadays, nanoparticle-based vaccines have attracted a lot of attention due to their high-efficiency in stimulating the humoral and cellular immune responses as well as their low risks for human consumption [8-10].

Silver nanoparticles (AgNPs) are widely used in recent years due to their low toxicity compared to alternative chemical compounds [11]. Moreover, using biological methods for nanoparticle synthesis such as by microorganisms and plants with their high potential of reducing metal are considered as eco-friendly, and cost-effective compared to conventional means of synthesis $[12,13]$. Although chemical methods are easier to perform than green synthesis and have higher efficiencies, their applications for nanoparticles synthesis are deemed more toxic and detrimental to the environment. Alternatively, plant extracts can be suitably scaled up for large scale biosynthesis of AgNPs in a controlled manner, according to their size, shape, and sensitivity [14-16]. So far, green synthesis of nanoparticles using plant extract of Andrachne cordifolia [17], Azadirachta indica [18], Medicago sativa[19], Gliricidia sepium [20], Aloe vera [21], Chenopodium album [22], Capsicum annuum [23], Citrus sinensis [4], Cinnamon zeylanicum [24] have been reported, to name a few.

Pimpinella anisum L. (Apiaceae), also known as aniseed or anise is an annual aromatic herb and a grassy plant with white flowers and small green to yellow seeds [25]. It is native to the eastern Mediterranean region while it has been used in traditional Iranian medicine as a remedy for carminative, neurologic, anticonvulsant, respiratory disorders, disinfection, 
epilepsy, galactagogue, anti-asthma, and dyspnea [26]. Anise extracts have flavonoids, phenols and proteins while they also have antioxidant activities $[26,27]$. The antioxidant activity of anise and the presence of agents such as flavonoids, proteins and phenols in it lead to the reduction of $\mathrm{Ag}^{+}$ions to nanoparticles $[16,28]$. The biosynthesis of silver nanoparticles is a complex process during which their quantity and quality are affected by many factors, such as $\mathrm{pH}$, temperature and time [29]. Here, we used anise extract as a reducing agent to produce AgNPs and evaluated its antibacterial activity against 4 bacterial pathogens of human, namely Escherichia coli, Salmonella typhimurium, Staphylococcus aureus and Enterococcus faecalis.

\section{MATERIALS AND METHODS}

\section{Anise Extract Preparation}

Anise plants were collected from a farm pasture at $\mathrm{Bu}-\mathrm{Ali}$ Sina University (Hamedan, Iran). Seeds and stems of anise were weighed carefully and rinsed with tap water to remove excess dirt, dust, and mud, and then dried at room temperature. After adding $100 \mathrm{~mL}$ of deionized double-distilled water, to $5 \mathrm{~g}$ anise seeds and stems and boiling them at $100^{\circ} \mathrm{C}$ for $3 \mathrm{~min}$, the mixture was cooled down at room temperature and then filtered with Whatman filter paper No. 2. The filtered extract was stored at $4^{\circ} \mathrm{C}[20]$.

\section{AgNPs Biosynthesis}

Pure $\mathrm{AgNO}_{3}$ was purchased from Titran Co. (Tehran, Iran). A solution of $1 \mathrm{mM} \mathrm{AgNO}_{3}$ was prepared for the biosynthesis of AgNPs. To complete the biosynthesis process, 5 $\mathrm{mL}$ of the anise extract were added to $250 \mathrm{ml} \mathrm{AgNO}_{3}(1 \mathrm{mM})$ in an Erlenmeyer flask, incubated in dark at room temperature on a shaker (140 rpm) for $96 \mathrm{~h} \mathrm{[20].}$

\section{UV-Vis Spectra Analysis}

The formation and stability of AgNPs were determined with PerkinElmerLamda-45 UV-Vis spectrophotometry. The calibration of UV-Vis spectrophotometry was carried out with distilled water. To test the accuracy of the device, $\mathrm{K}_{2} \mathrm{Cr}_{2} \mathrm{O}_{7}$ was used. The absorptions were monitored every $6 \mathrm{~h}$ for $96 \mathrm{~h}$.

\section{Transmission Electron Microscopy (TEM) Analysis}

The synthesized AgNPs were centrifuged 4 times (13'000 rpm, $10 \mathrm{~min}$ ) and washed with deionized distilled water and then put in a dark place at room temperature overnight to dry it out and obtain its powder form. Inside an Eppendorf vial, ethanol was added to the nanoparticles and the vial was placed in an ultrasonic device for $10 \mathrm{~min}$. Fifty $\mu \mathrm{l}$ of the sample was put on a copper grid, coated by carbon. The excessive sample was removed by a cone of a blotting paper and kept in a grid box to dry out. TEM (Zeiss, EM900, Germany) was used to analyze the formation and sizes of the nanoparticles.

\section{Fourier-Transform Infrared (FTIR) Spectroscopy}

To study the structure and formulation of the synthesized AgNPs and the extract, FTIR (PerkinElmer65) was used in the range of 4000-400 $\mathrm{cm}^{-1}$ with resolution of $0.01 \mathrm{~cm}^{-1}$ [30]. The powder of AgNPs and the extracts were prepared as described above for TEM. The obtained powders were then mixed with $\mathrm{KBr}$ with a ratio of $2 / 50$ to achieve a relatively homogenized solution. The solutions were then examined with FTIR spectrometer.

\section{Antimicrobial Activities}

Antibacterial assays were carried out on 4 bacterial human pathogens (i.e. E. coli, S. aureus, S. typhimurium and E. faecalis) by standard agar well diffusion and minimum inhibitory concentration (MIC)[31]. The unfrozen bacteria were incubated on brain heart broth (BHB) for $24 \mathrm{~h}$ at room temperature and then were cultured on brain heart agar (BHA) for $24 \mathrm{~h}$ at $37^{\circ} \mathrm{C}$. Densities of 0.5 Macfarlane were produced from each bacterial culture. The bacteria were swabbed uniformly onto separate Muller-Hinton agar (MHA) plates by sterile cotton swabs. For agar well diffusion method, aqueous AgNPs was produced from the powdered AgNPs in 50 and 100 $\mu \mathrm{g} / \mathrm{ml}$ densities. A sterile micropipette was used and $50 \mu \mathrm{l}$ of each density was poured onto each well in all plates, and also $20 \mu \mathrm{l}$ and $50 \mu \mathrm{l}$ of the direct non-centrifuged aqueous AgNPs were poured onto each well. For the disk diffusion method, 50 $\mu \mathrm{l}$ aqueous from the prepared powdered AgNPs and noncentrifuged AgNPs were added to blank disks. Three antibiotic disk papers, containing Ceftriaxone, Tetracycline, and Gentamicin were used as controls and cooperative effects of these antibiotics and AgNPs were examined by addition of 10 $\mu 1$ AgNPs to each antibiotic paper [32, 33]. Examination of the antibacterial activity of MHA plates were also done. It should be noted that using $10 \mu \mathrm{l}$ of AgNPs solution was more compatible with our antibiotic paper absorption capacity. All the plates were incubated for $24 \mathrm{~h}$ at $37^{\circ} \mathrm{C}$, except for $E$. faecalis that were cultured on BHA. After the incubations, the inhibition zones by the bacteria were measured in $\mathrm{mm}$. All the experiments were carried out for at least 4 replicates.

MIC of the AgNPs for evaluation of their antimicrobial activity was assessed by using standard 96-wells microplates [31]. MHB medium $(50 \mu \mathrm{l})$ was added to all wells except for $E$. faecalis in which BHI was used. AgNPs homogenized solutions $(50 \mu \mathrm{l})$ with $100 \mu \mathrm{g} / \mathrm{ml}$ densities were added to the first well and a serial dilution followed. Then, $10 \mu \mathrm{l}$ of each bacterial suspension was added onto all wells of a row to be incubated for $18 \mathrm{~h}$ at $37^{\circ} \mathrm{C}$. Finally, $50 \mu \mathrm{l}$ tetrazolium was added to the wells and re-incubated for additional $2 \mathrm{~h}$.

\section{RESULTS}

\section{The Reduction Process}

The observation of the first stage of AgNPs synthesis was carried out with naked eyes. After $15 \mathrm{~min}$ of adding the anise extract to AgNPs, the color changed from yellowish to brown and within $96 \mathrm{~h}$, the reduction was completed, making the color a stable clear yellow (Fig. 1). The reduction process was also detected by UV-Vis spectroscopy. AgNPs had absorption spectrum at different wavelengths ranging from $300-600 \mathrm{~nm}$, revealing a peak at $423 \mathrm{~nm}$. Fig. 2 shows an absorption graph of the synthesized AgNPs

\section{TEM Analyses}

The images obtained from TEM (Fig. 3) showed that the synthesized nanoparticles had different shapes such as circular, spherical, oval, and hexagonal as well as different sizes, ranging from 10 to $60 \mathrm{~nm}$ with an average size of $35 \mathrm{~nm}$ in diameter. As depicted in Fig. 1A, the AgNPs were capped by the reducing agents of the anise extract. These confining agents had stopped the growth of the AgNPs by shaping and stabilizing them. 


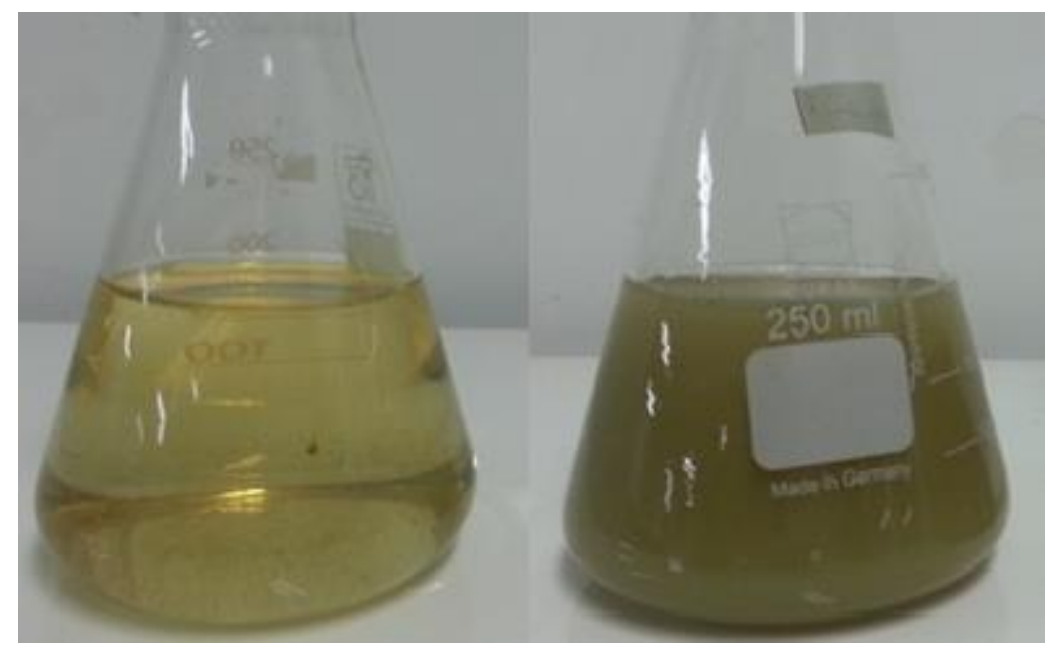

Fig. 1. Right: A flask containing AgNPs, 1 min after adding the anise extract. Left: Complete reduction, after $96 \mathrm{~h}$ of adding the anise extract

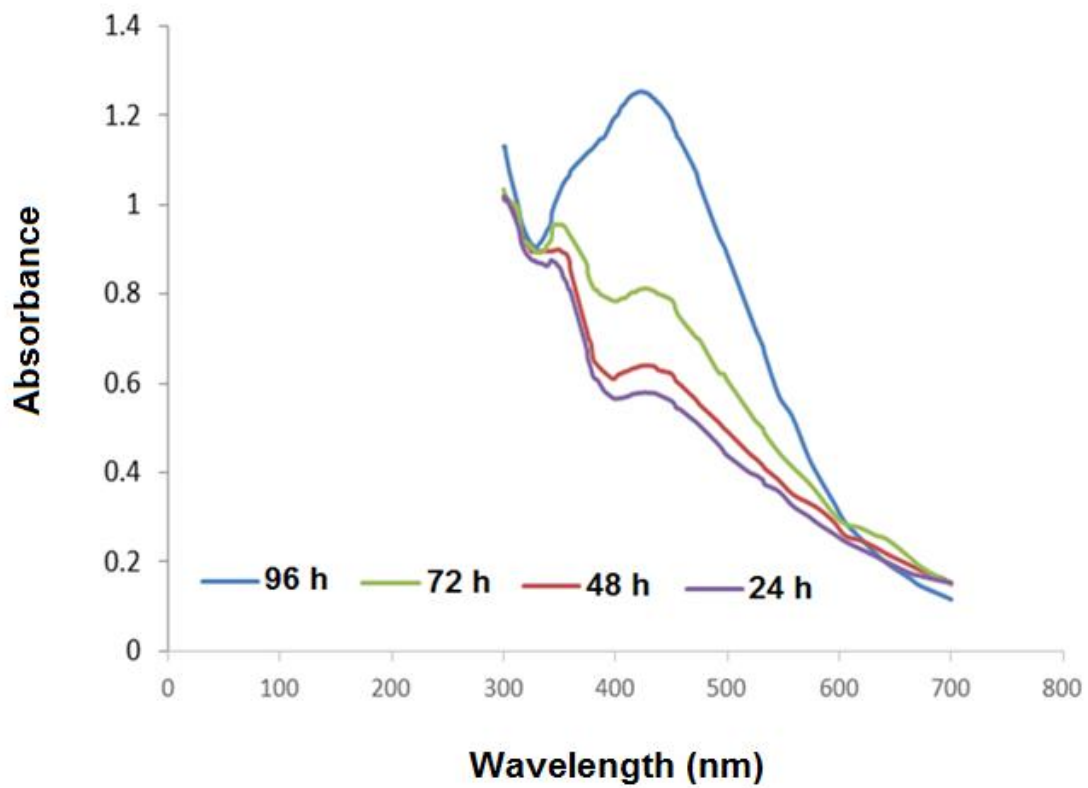

Fig. 2. The plot of UV-Vis spectrum of the synthesized AgNPs reduction process at 4 different time points (i.e. 24, 72, 48 and $96 \mathrm{~h}$ )

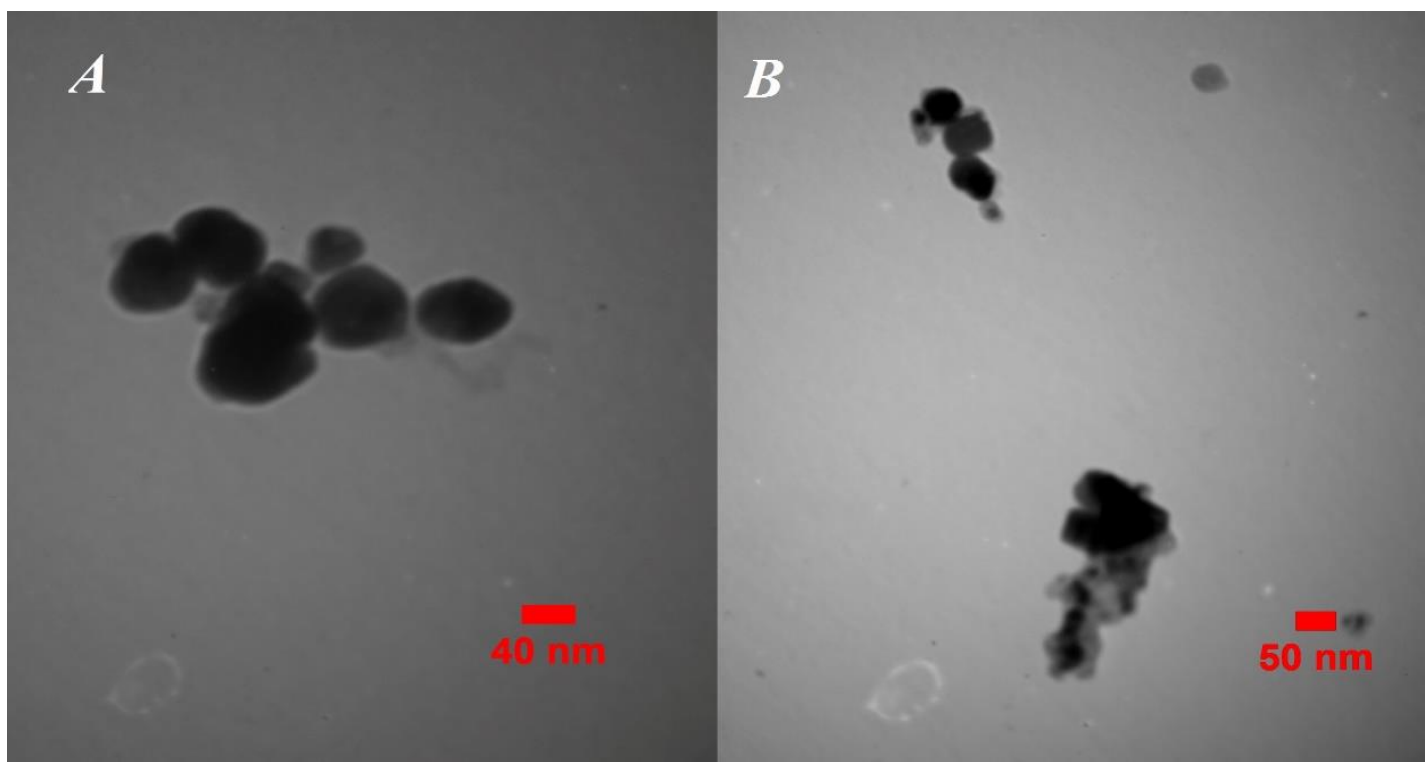

Fig. 3. TEM image of AgNPs recorded various sizes (scale bars: A: 40nm; B: 50nm) 
FTIR Spectroscopy Analyses

FTIR analyses of the extract before and after the addition of AgNPs showed strong bands at 1376.50, 1393.67, 1560.40, 1624.94 , and $1636.60 \mathrm{~cm}^{-1}$. A strong band at 1636.60 is attributed to carbonyl groups involved in nanoparticle production. Table 1, Fig.4 and Fig.5 show the FTIR spectra of anise before and after the reduction.

Table 1. FTIR absorption of Ag-NPs and their presumptive functional groups before and after the reduction.

\begin{tabular}{|c|c|c|c|c|c|}
\hline Absorption & Extract & Ag-NPs & Band & $\begin{array}{l}\text { Functional } \\
\text { groups }\end{array}$ & Reference \\
\hline 1030 & Appear & Decrease & C-N Stretch & $\begin{array}{l}\text { Aliphatic } \\
\text { amines }\end{array}$ & Jacob et al. 2011 [34] \\
\hline 1323 & Appear & Disappear & C-N Stretch & $\begin{array}{l}\text { Aromatic } \\
\text { amines }\end{array}$ & --------------- \\
\hline 1376 & Appear & Disappear & $\mathrm{C}-\mathrm{H}$ Bend & Alkenes & Kaviya et al. 2011 [4] \\
\hline 1463 & Appear & Disappear & $\mathrm{C}-\mathrm{H}$ Bend & Alkenes & Kaviya et al. 2011 [4] \\
\hline 1636 & -------- & Appear & $\mathrm{C}=\mathrm{C}$ Stretch & Alkenes & Ajitha et al. 2015 [28] \\
\hline 1648 & Appear & Increase & $\mathrm{C}=\mathrm{C}$ Stretch & Alkenes & Jain et al. 2009 [35] \\
\hline 2850 & Appear & Decrease & C-H Stretch & Alkenes & - \\
\hline 2919 & Appear & Decrease & N-H Stretch & $\begin{array}{l}\text { Secondary } \\
\text { amines }\end{array}$ & $\begin{array}{c}\text { Sadeghi and } \\
\text { Gholamhoseinpoor 2015 [1] }\end{array}$ \\
\hline
\end{tabular}

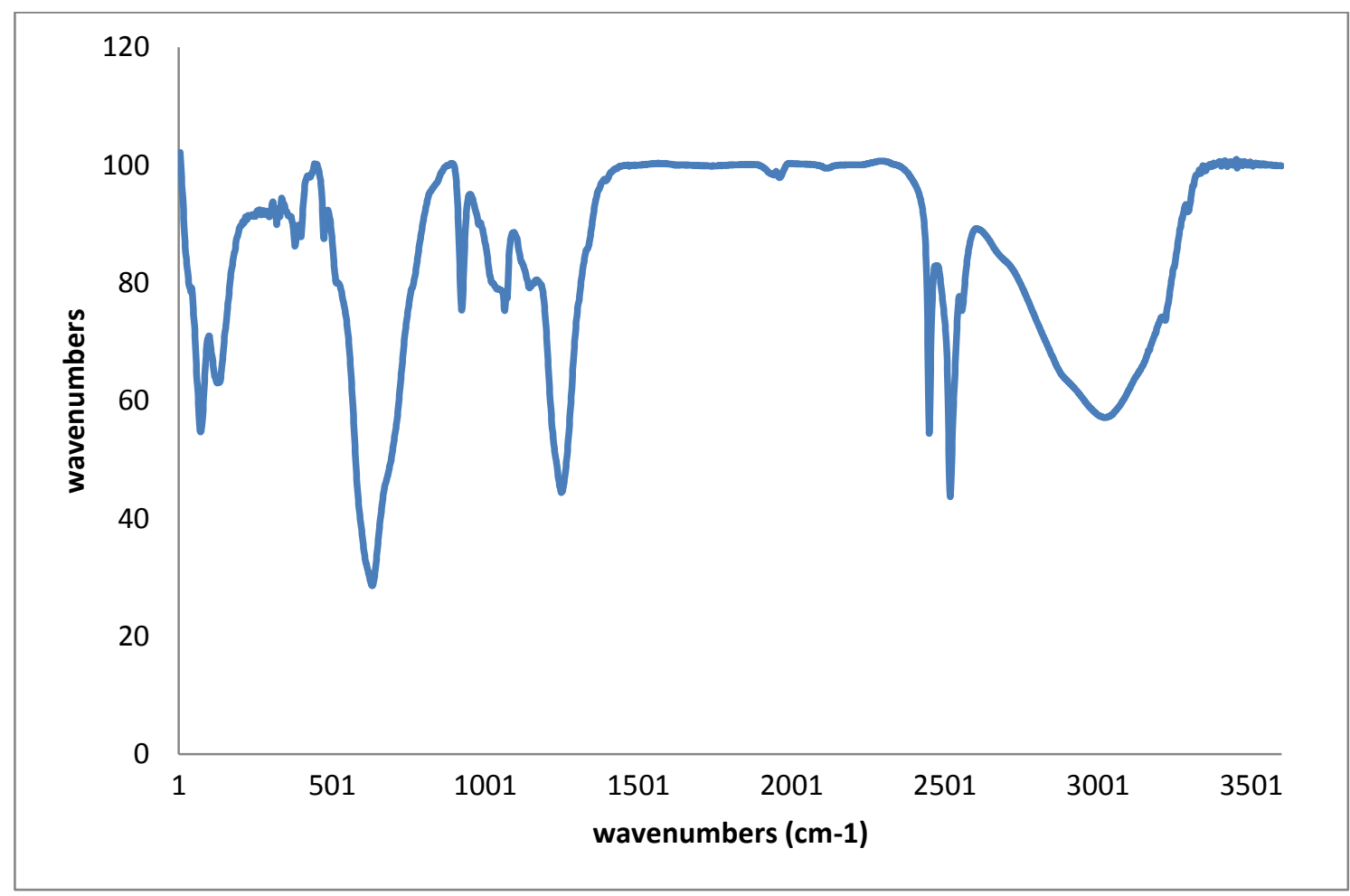

Fig. 4. FTIR spectra of the powdered anise extract 


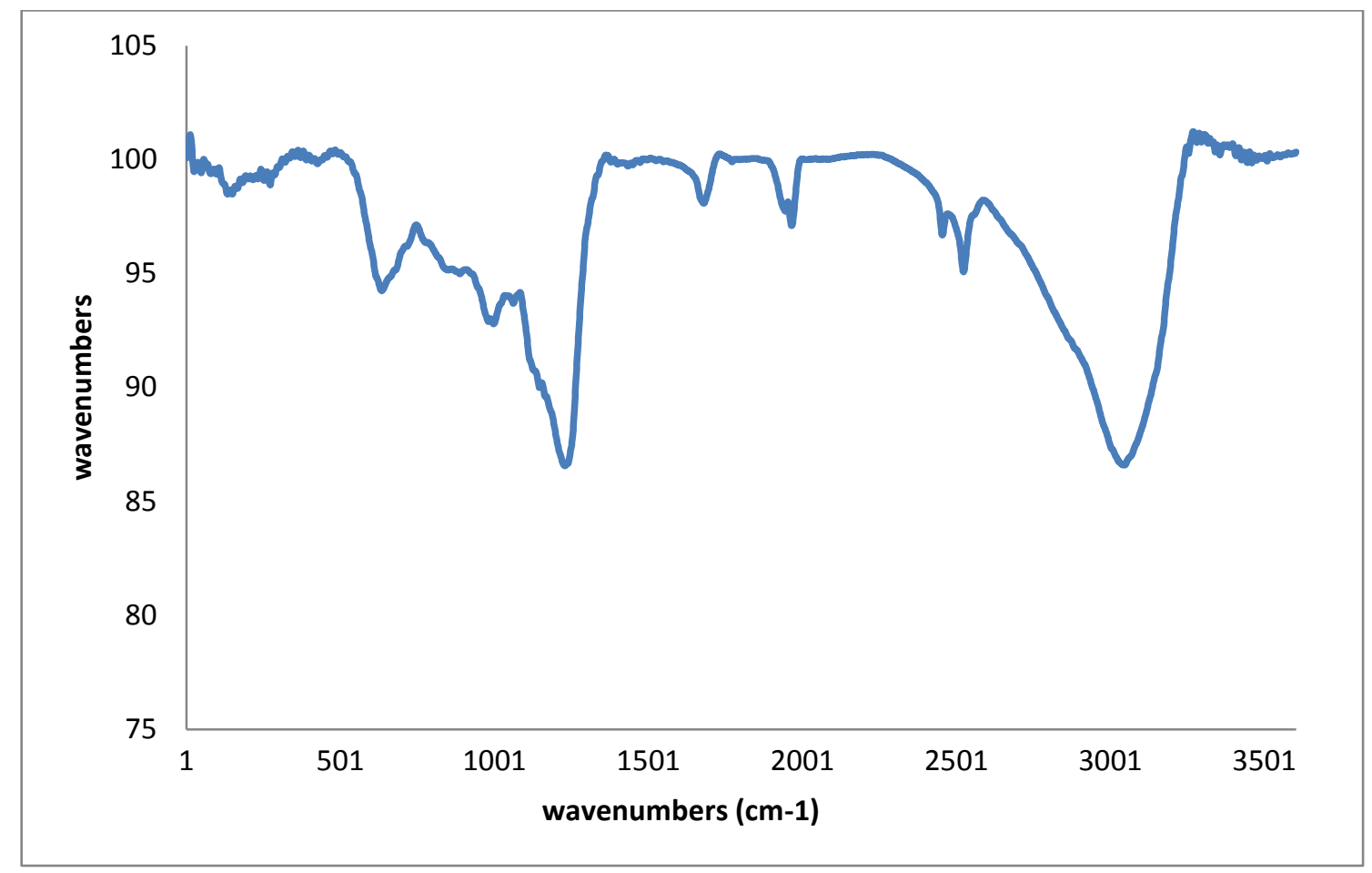

Fig. 5. FTIR spectra of the powdered AgNPs after the reduction

\section{Antimicrobial Assays}

The antimicrobial assays of the biosynthesized AgNPs against 4 bacterial human pathogens are shown in Table 2 and Fig. 6. These results indicated that the biosynthesized AgNPs had antimicrobial activities. The susceptibility to the antimicrobial property was observed for E. Coli, S. Aureus, S. Typhimurium in this order while no inhibitory effect was seen for E. faecalis. The MIC showed the lowest concentration of AgNPs for inhibition of E. coli, S. aureus and S. typhimurium as shown in Table 3. The combination of AgNPs and three types of antibiotics (i.e. Gentamicin, Erythromycin, and Ceftriaxone) against the same bacteria was examined which their results are indicated in Table 3 . The result showed that using AgNPs with antibiotic disk paper increased the antibiotic activity. This antibiotic activity was especially more prominent against E. faecalis which was resistant to Ag-NPs

Table 2. Zone of inhibition (mm) of produced AgNPs against bacterial pathogens.

\begin{tabular}{|c|c|c|c|c|c|c|c|c|c|}
\hline & \multicolumn{4}{|c|}{ Well diffusion } & \multicolumn{4}{|c|}{ Disk diffusion } & \multirow{3}{*}{$\begin{array}{c}\text { MIC } \\
(\mu \mathrm{g} / \mathrm{ml})\end{array}$} \\
\hline & \multicolumn{2}{|c|}{ Centrifuging } & \multicolumn{2}{|c|}{ Non-centrifuging } & \multicolumn{2}{|c|}{ Centrifuging } & \multicolumn{2}{|c|}{ Non-centrifuging } & \\
\hline & 100ppm & $50 \mathrm{ppm}$ & $50 \mu 1$ & $20 \mu 1$ & 100ppm & $50 \mathrm{ppm}$ & $50 \mu 1$ & $20 \mu 1$ & \\
\hline E. coli & $10 \pm 0.0$ & $8.66 \pm 2.08$ & $10.33 \pm 0.57$ & $8 \pm 2.00$ & $10 \pm 1.00$ & $8.66 \pm 0.57$ & $11.33 \pm 1.52$ & $7.33 \pm 2.08$ & $50 \pm 00$ \\
\hline S. aureus & $10 \pm 1.0$ & $8.66 \pm 1.15$ & $10.33 \pm 2.08$ & $8.66 \pm 3.05$ & $10.33 \pm 0.57$ & $7 \pm 1.00$ & $6 \pm 1.00$ & $7 \pm 1.00$ & $50 \pm 00$ \\
\hline S. typhi & $8.6 \pm 0.57$ & $8.33 \pm 1.52$ & $10 \pm 1.73$ & $7 \pm 1.00$ & $8.66 \pm 0.57$ & $7.66 \pm 0.57$ & $8.66 \pm 0.57$ & $7 \pm 1.00$ & $12.5 \pm 00$ \\
\hline E. faecalis & 0 & 0 & 0 & 0 & 0 & 0 & 0 & 0 & ------ \\
\hline
\end{tabular}

Table 3. Zones of inhibition (in mm) of the combination of AgNPs and three types of antibiotic

\begin{tabular}{|c|c|c|c|c|c|c|c|}
\hline & Water & Gentamicin & Erythromycin & Ceftriaxone & $\begin{array}{c}\text { Gentamicin } \\
\text { +AgNPs }\end{array}$ & $\begin{array}{c}\text { Erythromycin } \\
\text { +AgNPs }\end{array}$ & $\begin{array}{c}\text { Ceftriaxone } \\
\text { +AgNPs }\end{array}$ \\
\hline E. coli & 0 & $27 \pm 1.73$ & $11 \pm 1.00$ & $37 \pm 2.64$ & $30.33 \pm 1.52$ & $22 \pm 1.00$ & $37.33 \pm 57$ \\
\hline S. aureus & 0 & $25 \pm 0.00$ & $27.66 \pm 0.57$ & $24.33 \pm 0.57$ & $28.66 \pm 1.52$ & $36.33 \pm 1.52$ & $37.33 \pm 1.52$ \\
\hline S. typhi & 0 & $22.66 \pm 0.57$ & $9.66 \pm 1.52$ & $31.33 \pm 1.52$ & $23.33 \pm 0.57$ & $13 \pm 1.00$ & $34.33 \pm 1.52$ \\
\hline E. faecalis & 0 & $10.66 \pm 1.15$ & $14.66 \pm 0.57$ & $18 \pm 2.00$ & $23.66 \pm 1.52$ & $19.33 \pm 1.52$ & $26.66 \pm 1.52$ \\
\hline
\end{tabular}




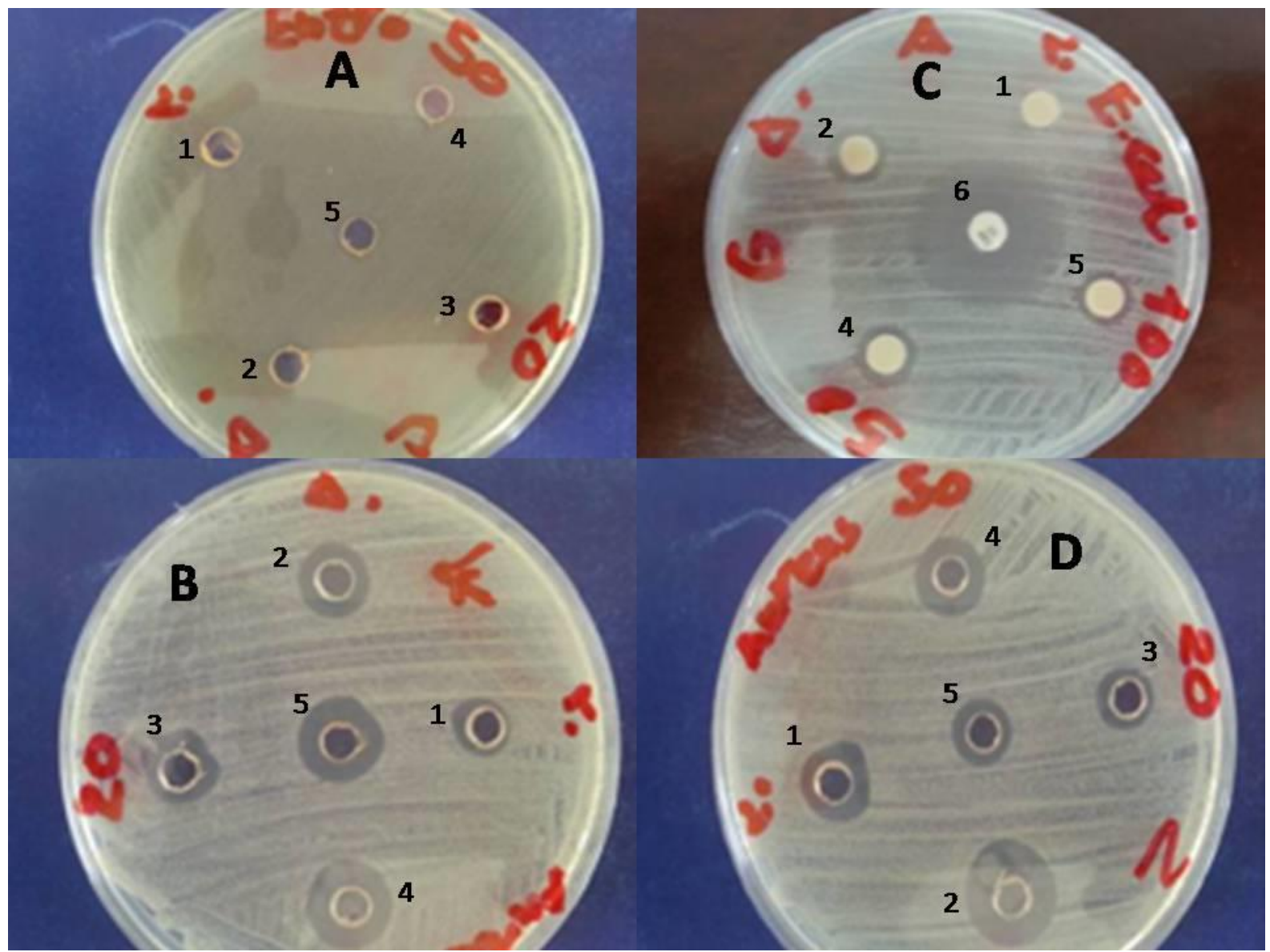

Fig. 6. Antibacterial activities of the synthesized AgNPs in varies densities and volumes on A: E. faecalis, B: S. typhimurium, C: E. coli, D: $S$. aureus (1: $20 \mu \mathrm{l} ; 2: 50 \mu \mathrm{l} ; 3: 20 \mathrm{ppm} ; 4: 50 \mathrm{ppm} ; 5: 100 \mathrm{ppm}$; 6: Gentamicin)

\section{DISCUSSION}

In this study, we presented the green synthesis of AgNPs, produced by anise as an environmentally-friendly method and examined its antibacterial activity. Aqueous extracts from anise seed have a potential capacity toward silver nitrate reduction and production of AgNPs. The study of the synthesis process by UV-Vis at different time points and absorption intervals confirmed the production of AgNPs. The FTIR graph pointed out the reducing agents of the extract. These results also showed that the FTIR graph of anise extract had paramount differences from the graph of nanoparticles biosynthesized. These differences can be described as an increase of absorption, an increase in the length of peaks, and elimination of some peaks in the graph that may be resulted from the centrifugation, washing of the nanoparticles, or breaking of the chemical bonds of the extract after reduction of the nanoparticles. The band at 1376.50 and 1393.67 corresponded to $\mathrm{C}-\mathrm{H}$ of alkane's. The band at 1560.40 can be assigned to the $\mathrm{N}-\mathrm{H}$ at secondary amides while the band at 1648.39 can be attributed to $\mathrm{C}=\mathrm{C}$ alkenes.

The spherical, circular, and hexagonal nanoparticles exhibited antibacterial activities. These nanoparticles are assumed to adhere to the bacterial cell wall and penetrate through the cell membrane. This can cause the destruction of the bacterial cell wall and disruption of the membrane permeability, leading to the cell death. Considering that the antibacterial efficacy has a significant relationship with nanoparticle size and concentration, the small size and high concentration of AgNPs was proved to be more effective. This ability was increased by cooperation with antibiotics such as Ceftriaxone, Erythromycin, and Gentamicin and this capability was more pronounced during the cooperation of AgNPs with Ceftriaxone. E. coli was more sensitive compared to other bacteria and E. faecalis was strongly resistant to AgNPs. The reason behind the resistance of $E$. faecalis to silver particles is still unclear [36]. On the other hand, these organisms have shown resistance to many other conventional antimicrobial substances [37].

Collectively, the metallic nanoparticles could be considered as novel alternatives for antibiotics with potentially lower side effects and more safety over the conventional chemical antibiotics. Moreover, using these nanoparticles in preparation and production of the new generation of vaccines has gained more attention. For instance, Manaf et al [38], have worked on a vaccine against $S$. aureus tested in mice. This vaccine which was made from inactivated $S$. aureus in combination with $\mathrm{AgNO}_{3}$, has been shown to be more effective than a vaccine with $S$. aureus alone and has led to an increase in $\mathrm{T}$-cell and B-cell counts while raising the rate of phagocytes and antibodies in the mice blood serum. Also, the positive effects of such nanoparticles on the respiratory viruses have been demonstrated [39, 40]. Furthermore, it has been shown that when nanoparticles are used as adjuvants in vaccine production, they lead to increased antigen presentation and stronger immunity than common adjuvants [40, 41]. It should 
be noted that the use of nanoparticles causes the vaccine to be released at a slower rate, which in turn results in a stronger humoral response with lower toxicity $[42,43]$. Therefore, aside from the observed antibacterial effects of the produced AgNPs against both Gram-positive (e.g. S. aureus) and Gram-negative (e.g. E. coli) bacteria, it is envisaged that these AgNPs could have potentially vaccine adjuvant properties which requires further studies.

\section{ACKNOWLEDGEMENT}

This research was funded by Islamic Azad University of Boroujerd. The authors would like to express their gratitude to Mr. Behnam Lak and Mr. Mehdi Moradi for their helps in proofreading of the manuscript.

\section{CONFLICT OF INTEREST}

The authors declare that they have no conflict of interest.

\section{REFERENCES}

1. Sadeghi B, Gholamhoseinpoor F. A study on the stability and green synthesis of silver nanoparticles using Ziziphora tenuior $(\mathrm{Zt})$ extract at room temperature. Spectrochimica Acta Part A: Molecular and Biomolecular $\quad$ Spectroscopy. 2015;134:310-5. doi:https://doi.org/10.1016/j.saa.2014.06.046.

2. Nikalje AP. Nanotechnology and its applications in medicine. Med chem. 2015;5(2):081-9.

3. Ankanna S, Prasad TNVKV, Elumalai K, Savithramma N. Production of biogenic silver nanoparticles using Boswellia Ovalifoliolata stem bark. Digest Journal of Nanomaterials and Biostructures. 2010;5:369-72.

4. Kaviya S, Santhanalakshmi J, Viswanathan B, Muthumary J, Srinivasan $\mathrm{K}$. Biosynthesis of silver nanoparticles using citrus sinensis peel extract and its antibacterial activity. Spectrochimica Acta Part A: Molecular and $\begin{array}{lll}\text { Biomolecular } & \text { Spectroscopy. } & \text { 2011;79(3):594-8. }\end{array}$ doi:https://doi.org/10.1016/j.saa.2011.03.040.

5. Irvine DJ, Hanson MC, Rakhra K, Tokatlian T. Synthetic Nanoparticles for Vaccines and Immunotherapy. Chemical Reviews. 2015;115(19):1110946. doi:10.1021/acs.chemrev.5b00109.

6. Szeto GL, Lavik EB. Materials design at the interface of nanoparticles and innate immunity. Journal of Materials Chemistry B. 2016;4(9):1610-8. doi:10.1039/C5TB01825K.

7. Zhu M, Wang R, Nie G. Applications of nanomaterials as vaccine adjuvants. Human Vaccines \& Immunotherapeutics. 2014;10(9):2761-74. doi:10.4161/hv.29589.

8. Pati R, Shevtsov M, Sonawane A. Nanoparticle Vaccines Against Infectious Diseases. Frontiers in immunology. 2018;9:2224-. doi:10.3389/fimmu.2018.02224.

9. Niu Y, Yu M, Hartono SB, Yang J, Xu H, Zhang H et al. Nanoparticles Mimicking Viral Surface Topography for Enhanced Cellular Delivery. Advanced Materials. 2013;25(43):6233-7. doi:10.1002/adma.201302737.

10. Fogarty J, Swartz J. The exciting potential of modular nanoparticles for rapid development of highly effective vaccines. Current Opinion in Chemical Engineering. 2018;19:1-8. doi:10.1016/j.coche.2017.11.001.

11. Choi O, Deng KK, Kim N-J, Ross L, Surampalli RY, Hu Z. The inhibitory effects of silver nanoparticles, silver ions, and silver chloride colloids on microbial growth. Water Research. 2008;42(12):3066-74. doi:https://doi.org/10.1016/j.watres.2008.02.021.

12. Shanmugam R, Chelladurai M, Paulkumar K, Vanaja M, Gnanajobitha G, Gurusamy A. Algae Mediated Green Fabrication of Silver Nanoparticles and Examination of Its Antifungal Activity against Clinical Pathogens. International Journal of Metals. 2014;2014:1-8. doi:10.1155/2014/692643.

13. Nabikhan A, Kandasamy K, Raj A, Alikunhi NM. Synthesis of antimicrobial silver nanoparticles by callus and leaf extracts from saltmarsh plant, Sesuvium portulacastrum L. Colloids Surf B Biointerfaces. 2010;79(2):488-93. doi:10.1016/j.colsurfb.2010.05.018.

14. Gnanadesigan M, Anand M, Ravikumar S, Maruthupandy M, Syed Ali $\mathrm{M}$, Vijayakumar V et al. Antibacterial potential of biosynthesised silver nanoparticles using Avicennia marina mangrove plant. Applied Nanoscience. 2012;2(2):143-7. doi:10.1007/s13204-011-0048-6.
15. Sangaru SS, Ahmad A, Sastry M. Geranium Leaf Assisted Biosynthesis of Silver Nanoparticles. Biotechnology progress. 2003;19:1627-31. doi:10.1021/bp034070w.

16. Song JY, Kim BS. Rapid biological synthesis of silver nanoparticles using plant leaf extracts. Bioprocess Biosyst Eng. 2009;32(1):79-84. doi:10.1007/s00449-008-0224-6.

17. Karimi Zarchi AA, Mokhtari N, Arfan M, Rehman T, Ali M, Amini M et al. A sunlight-induced method for rapid biosynthesis of silver nanoparticles using an Andrachnea chordifolia ethanol extract. Applied Physics A. 2011;103(2):349-53. doi:10.1007/s00339-011-6259-6.

18. Tripathy A, Raichur A, Chandrasekaran N, Tc P, Mukherjee A. Process variables in biomimetic synthesis of silver nanoparticles by aqueous extract of Azadirachta indica (Neem) leaves. Journal of Nanoparticle Research. 2009;12:237-46. doi:10.1007/s11051-009-9602-5.

19. Montes MO, Mayoral A, Deepak FL, Parsons JG, Jose-Yacamán M, Peralta-Videa JR et al. Anisotropic gold nanoparticles and gold plates biosynthesis using alfalfa extracts. Journal of Nanoparticle Research. 2011;13(8):3113-21. doi:10.1007/s11051-011-0230-5.

20. Raut Rajesh W, Lakkakula Jaya R, Kolekar Niranjan S, Mendhulkar Vijay D, Kashid Sahebrao B. Phytosynthesis of Silver Nanoparticle Using Gliricidia sepium (Jacq.). Current Nanoscience. 2009;5(1):117-22. doi:http://dx.doi.org/10.2174/157341309787314674.

21. Chandran SP, Chaudhary M, Pasricha R, Ahmad A, Sastry M. Synthesis of gold nanotriangles and silver nanoparticles using Aloe vera plant extract. Biotechnol Prog. 2006;22(2):577-83. doi:10.1021/bp0501423.

22. Dwivedi A, Gopal K. Biosynthesis of silver and gold nanoparticles using Chenopodium album leaf extract. Colloids and Surfaces Aphysicochemical and Engineering Aspects - COLLOID SURFACE A. 2010;369:27-33. doi:10.1016/j.colsurfa.2010.07.020.

23. Li S, Shen Y, Xie A, Yu X, Qiu L, Zhang L et al. Green synthesis of silver nanoparticles using Capsicum annuum L. extract. Green Chemistry GREEN CHEM. 2007;9. doi:10.1039/b615357g.

24. Sathishkumar M, Sneha K, Won SW, Cho CW, Kim S, Yun YS. Cinnamon zeylanicum bark extract and powder mediated green synthesis of nano-crystalline silver particles and its bactericidal activity. Colloids and $\begin{array}{llll}\text { Surfaces } & \text { B: } & \text { Biointerfaces. } & \text { 2009;73(2):332-8. }\end{array}$ doi:https://doi.org/10.1016/j.colsurfb.2009.06.005.

25. Pourgholami MH, Majzoob S, Javadi M, Kamalinejad M, Fanaee GHR, Sayyah M. The fruit essential oil of Pimpinella anisum exerts anticonvulsant effects in mice. Journal of Ethnopharmacology. 1999;66(2):211-5. doi:https://doi.org/10.1016/S0378-8741(98)00161-5. 26. Shojaii A, Abdollahi Fard M. Review of Pharmacological Properties and Chemical Constituents of Pimpinella anisum. ISRN pharmaceutics. 2012;2012:510795-. doi:10.5402/2012/510795.

27. Kunzemann J, Herrmann K. [Isolation and identification of flavon(ol)O-glycosides in caraway (Carum carvi L.), fennel (Foeniculum vulgare Mill.), anise (Pimpinella anisum L.), and coriander (Coriandrum sativum L.), and of flavon-C-glycosides in anise. I. Phenolics of spices (author's transl)]. Z Lebensm Unters Forsch. 1977;164(3):194-200. doi: $10.1007 / \mathrm{bf} 01263030$.

28. Ajitha B, Ashok Kumar Reddy Y, Sreedhara Reddy P. Green synthesis and characterization of silver nanoparticles using Lantana camara leaf extract. Mater Sci Eng C Mater Biol Appl. 2015;49:373-81. doi:10.1016/j.msec.2015.01.035.

29. Puiso J, Jonkuviene D, Macioniene I, Salomskiene J, Jasutiene I, Kondrotas R. Biosynthesis of silver nanoparticles using lingonberry and cranberry juices and their antimicrobial activity. Colloids Surf B Biointerfaces. 2014;121:214-21. doi:10.1016/j.colsurfb.2014.05.001.

30. Jyoti K, Baunthiyal M, Singh A. Characterization of silver nanoparticles synthesized using Urtica dioica Linn. leaves and their synergistic effects with antibiotics. Journal of Radiation Research and Applied Sciences. 2016;9(3):217-27. doi:https://doi.org/10.1016/j.jrras.2015.10.002.

31. Loo YY, Rukayadi Y, Nor-Khaizura M-A-R, Kuan CH, Chieng BW, Nishibuchi M et al. In Vitro Antimicrobial Activity of Green Synthesized Silver Nanoparticles Against Selected Gram-negative Foodborne Pathogens. Frontiers in microbiology. 2018;9:1555doi:10.3389/fmicb.2018.01555.

32. Mohsen E, el Borady O, Mohamed M, Fahim I. Synthesis and characterization of ciprofloxacin loaded silver nanoparticles and investigation of their antibacterial effect. Journal of Radiation Research and Applied Sciences. 2020;13:416-25. doi:10.1080/16878507.2020.1748941.

33. Loo YY, Rukayadi Y, Nor-Khaizura M-A-R, Kuan CH, Chieng BW, Nishibuchi M et al. In Vitro Antimicrobial Activity of Green Synthesized Silver Nanoparticles Against Selected Gram-negative Foodborne Pathogens. Frontiers in Microbiology. 2018;9(1555). doi:10.3389/fmicb.2018.01555. 
34. Jacob SJ, Finub JS, Narayanan A. Synthesis of silver nanoparticles using Piper longum leaf extracts and its cytotoxic activity against Hep-2 cell line. Colloids and surfaces B, Biointerfaces. 2012;91:212-4. doi:10.1016/j.colsurfb.2011.11.001.

35. Jain D, Daima HK, Kachhwaha S, Kothari S. Synthesis of plantmediated silver nanoparticles using papaya fruit extract and evaluation of their anti microbial activities. Digest journal of nanomaterials and biostructures. 2009;4(3):557-63.

36. Cui J, Sun Q, Duan M, Liu D, Fan W. Establishment and characterization of silver-resistant Enterococcus faecalis. Folia Microbiol (Praha). 2020. doi:10.1007/s12223-020-00778-5.

37. Miller WR, Munita JM, Arias CA. Mechanisms of antibiotic resistance in enterococci. Expert review of anti-infective therapy. 2014;12(10):122136. doi:10.1586/14787210.2014.956092.

38. Manaf R. Impact of silver nanoparticles on immune Responses as Vaccine against Activated Staphylococcus aureus Bacteria. International Journal of Science and Research (IJSR). 2017;6:280-4. doi:10.21275/ART20176269.

39. Sanchez-Guzman D, Le Guen P, Villeret B, Sola N, Le Borgne R,
Guyard A et al. Silver nanoparticle-adjuvanted vaccine protects against lethal influenza infection through inducing BALT and IgA-mediated mucosal immunity. Biomaterials. 2019;217:119308. doi:https://doi.org/10.1016/j.biomaterials.2019.119308.

40. Al-Halifa S, Gauthier L, Arpin D, Bourgault S, Archambault D. Nanoparticle-Based Vaccines Against Respiratory Viruses. Frontiers in Immunology. 2019;10(22). doi:10.3389/fimmu.2019.00022.

41. Gregory AE, Titball R, Williamson D. Vaccine delivery using nanoparticles. Front Cell Infect Microbiol. 2013;3:13doi:10.3389/fcimb.2013.00013.

42. Demento SL, Cui W, Criscione JM, Stern E, Tulipan J, Kaech SM et al. Role of sustained antigen release from nanoparticle vaccines in shaping the $\mathrm{T}$ cell memory phenotype. Biomaterials. 2012;33(19):4957-64. doi:10.1016/j.biomaterials.2012.03.041.

43. Asgary V, Shoari A, Baghbani-Arani F, Sadat Shandiz SA, Khosravy MS, Janani A et al. Green synthesis and evaluation of silver nanoparticles as adjuvant in rabies veterinary vaccine. Int J Nanomedicine. 2016;11:3597605. doi:10.2147/IJN.S109098. 